\title{
A LUDICIDADE DA CRIANÇA E SUA RELAÇÃO COM O CONTEXTO FAMILIAR ${ }^{1}$
}

\author{
Raquel Conte Poletto
}

\begin{abstract}
RESUMO. Esse artigo é resultado de uma pesquisa que procurou investigar como o lúdico aparece no contexto diário da vida das crianças em situação de pobreza econômica. Buscou-se investigar os brinquedos, brincadeiras, o tempo, o espaço e as companhias preferidas pelas crianças, bem como a visão de seus familiares, através de entrevistas estruturadas. As crianças foram escolhidas aleatoriamente, em duas escolas públicas de Caxias do Sul, num total de quarenta, com idades entre 7 e 10 anos. Os resultados apontam para os aspectos protetivos e os de risco. As conclusões indicam a necessidade de novas pesquisas de observação in loco das interações entre as crianças e seus respectivos familiares, bem como a possibilidade de estruturação de programas na rede municipal que beneficiem essas interações através do lúdico.
\end{abstract}

Palavras-chave: brincar, família, interações.

\section{CHILDREN'S LUDIC BEHAVIOR AND THEIR RELATIONSHIP IN THE FAMILY CONTEXT}

\begin{abstract}
This study is the result of an investigation of how ludic aspects are shown in the everyday context of a child and caretakers/family members from low income classes. The purpose of the study was to investigate children's favorite toys and games, the time, spaces and favorite companions, as well as their family members view, through structured interviews. Forty children from 7 to 10 years of age were chosen at random at two public schools in the city of Caxias do Sul. The results indicate the protective and risky aspects. The conclusions point to a need for new observation researches of the interaction among children and their families in loc, and the possibility of offering structured programs in public schools in order to add benefits to these interactions with ludic approaches.
\end{abstract}

Key words: play, family, interactions.

Cada vez mais os meios de comunicação veiculam os altos índices de crianças na rua, do trabalho infantil, bem como as numerosas situações de negligência e abusos dos pais em relação a seus filhos. Sabe-se que o lúdico é um instrumento que permite a inserção da criança na cultura e através do qual se podem permear suas vivências internas com a realidade externa. É um facilitador para a interação com o meio, embora seja muito pouco explorado. Apesar de as crianças menos favorecidas economicamente viverem em situações de estresse e risco constantes, o lúdico pode vir a ser um instrumento de promoção de resiliência, conforme o seu emprego.

Segundo Nunes (1994), o conceito de infância varia em diferentes classes e culturas, o que gera expectativas e demandas diversas quanto ao desenvolvimento infantil; no entanto, há unanimidade quanto ao reconhecimento da importância do meio nesse desenvolvimento. A análise do ambiente da criança em relação ao seu desenvolvimento tem levado a correlacionar o desenvolvimento de habilidades e competências com os estímulos ambientais.

Alguns autores que estudam a resiliência apontam para o brincar como um dos fatores de proteção à criança. O brincar é uma atividade culturalmente definida e representa uma necessidade para o adequado desenvolvimento infantil. As crianças violadas em seus direitos deixam de brincar para trabalhar, ocupando papéis familiares que não lhes são próprios.

A pobreza e o preconceito podem ser considerados como fatores que envolvem aspectos tão adversos que muitas vezes se tornam crônicos, interagindo de forma negativa no desenvolvimento da

1 Apoio financeiro da FAPERGS

* Psicóloga, Professora Titular do Departamento de Psicologia da Universidade de Caxias do Sul-UCS. Mestre em Psicologia do Desenvolvimento, especialista em Psicanálise das Configurações Vinculares pelo Instituto Contemporâneo de Porto Alegre e Formação no Centro de Estudos Psicanalíticos de Porto Alegre. 
criança. As crianças que vivem em situação de pobreza muitas vezes não têm suas necessidades básicas atendidas por adultos responsivos; então a infância é deixada de lado e elas perdem suas características infantis. A falta de uma estrutura familiar acarreta ausência ou deficiência das funções e papéis dos indivíduos. A carência generalizada das pessoas em situação de pobreza contribui para isolar, ignorar ou negar situações e instrumentos sociais que permitiriam uma maior inserção no contexto social mais amplo.

Alguns autores, como Alves, Koller, Silva, Santos, Silva, Reppold e Prade (2001) apontam para a necessidade de abordar o tema do lúdico junto ao contexto familiar, uma vez que tal abordagem pode direcionar para estratégias que promovam a resiliência. Realmente sabe-se pouco a respeito do brincar das crianças em situação de pobreza, bem como a respeito da visão dos familiares e de suas interações com as seus filhos em atividades lúdicas.

\section{A HISTÓRIA DO BRINQUEDO}

De acordo com Oliveira (1984), o interesse pela origem dos brinquedos há muito tempo tem levado pesquisadores a desvendar pelo mundo afora resquícios e retratos que pudessem associar o fenômeno do brinquedo e o ato de brincar ao contexto histórico dos diversos grupos sociais. A partir da Segunda Guerra Mundial houve maior incorporação de brinquedos de plástico. Começa aí, também, o aumento da violência nas ruas, e as crianças passam a ficar presas em casa, tendo a televisão e os brinquedos como companhia, já que as mulheres começaram a ter o direito e o dever de trabalhar para garantir a subsistência familiar. Dessa forma, os brinquedos industrializados passaram a ser os mais adequados à ordem doméstica, justamente por serem práticos e funcionais, não provocarem sujeira e, quando quebrados, virarem lixo e poderem ser substituídos por outros. Com a crescente industrialização do brinquedo, cada vez mais "aumentam" as opções de brincar; aumento questionável, se for considerado que os brinquedos não-estruturados são os que permitem um maior uso da imaginação e da criatividade.

\section{O BRINCAR COMO FATOR DE PROTEÇÃO}

Poletto e Koller (2002) afirmam que o desenvolvimento implica tarefas fundamentais, complexas e dinâmicas, ocorrendo pela interação de forças genéticas e ambientais. As crianças se desenvolvem em interação com pessoas, instituições, creches, escolas, comunidades, famílias, entre outras. De acordo com Kotliarenco (1997/2002), o jogo pode estimular e reforçar as situações familiares e comunitárias, assim como estimular as competências cognitivas. O processo de socialização, ao qual se vêem expostas as crianças em situação de pobreza, tem sido descrito como empobrecedor e punitivo. A consequiência é que as crianças não se desenvolvem bem nas tarefas da vida. Uma das áreas em que a pobreza tem interferido é a do desenvolvimento das crianças, conforme se verifica com a ausência do jogo sociodramático ou jogo de regras. Percebe-se que essas crianças têm prejuízos no desenvolvimento cognitivo e lingüístico.

Para Brougère (1994), os brinquedos também possibilitam a manipulação das imagens, das significações simbólicas, que constituem uma parte da impregnação cultural à qual a criança está submetida. $\mathrm{O}$ brinquedo deve ser considerado em sua especificidade. A criança, na maior parte das vezes, não se contenta em contemplar ou registrar as imagens: ela as manipula na brincadeira e, ao fazê-lo, transforma-as e lhes dá novas significações. Quanto mais ativa for a apropriação, mais forte ela se torna. $\mathrm{O}$ valor lúdico reforça a eficácia simbólica do brinquedo. Isso é que faz a especificidade do brinquedo em relação a outros suportes culturais: a relação ativa introduzida pela criança. A representação é transformada diversas vezes e posteriormente é personalizada. Através do brinquedo a criança constrói suas relações com o objeto, relações que constituem esquemas que ela reproduzirá com outros objetos na sua vida futura. Sendo esse objeto permeado pelo adulto, toda relação com o brinquedo pressupõe uma relação com ele e com as imagens dos discursos (produzidos pelos adultos e pelas crianças).

\section{ABORDAGENS TEÓRICAS SOBRE O BRINCAR}

Três grandes vertentes teóricas oferecem subsídios sobre o lúdico, atribuindo a ele significados e funções diferentes: as visões sócio-histórica, cognitiva e psicanalítica.

Para a visão sócio-histórica, o brincar ocorre num contexto cultural, sendo impossível dissociar afeto e cognição, forma e conteúdo, da ação humana. Para Vygotsky (1989), o brinquedo desempenha várias funções no desenvolvimento, como: preencher as diversas necessidades da criança, permitir $o$ envolvimento da criança num mundo ilusório, favorecer a ação na esfera cognitiva, fornecer um estágio de transição entre pensamento e objeto real, 
possibilitar maior autocontrole da criança, uma vez que lida com conflitos relacionados às regras sociais e ao seus próprios impulsos.

$\mathrm{Na}$ perspectiva cognitiva, o brinquedo e o ato de brincar, conforme Amorim, Oliveira e Mariotto (1997), constituem-se em vínculos importantes na construção do conhecimento, pois o sujeito internaliza sua realidade através da simbolização. Como "prazer funcional", o brinquedo faz do ato de brincar uma oportunidade de melhora e domínio, de que, quando adulto, o homem vai necessitar. Piaget traz grandes contribuições para a psicologia cognitiva, analisando o jogo em relação à vida mental, traçando um paralelo entre os estágios de desenvolvimento cognitivo e o aparecimento de diferentes tipos de jogos. Propõe quatro grandes tipos de estruturas para caracterizar os jogos infantis: jogos de exercícios, jogo simbólico, jogos de regras, jogos de criação.

A psicanálise remete o brincar ao inconsciente. De acordo com Winnicott (1982), as crianças têm prazer em todas as experiências de brincadeiras físicas e emocionais. Além disso, brincam também para dominar angústias e controlar idéias ou impulsos que conduzem à angústia. No espaço do brincar a criança comunica sentimentos, idéias, fantasias, intercambiando o real e o imaginário.

Para Zamberlan e Biasoli-Alves (1997), o papel dos pais, além de ser o de prover bens, sustento dos filhos, educação informal e preparo à educação formal, consiste em transmitir valores culturais de diversas naturezas (religiosos, morais, tradicionais, acadêmicos). Os pais têm a missão de dividir afazeres e controlar rotinas, as quais são assimiladas pela prole no desenvolvimento de sua personalidade. A partir da segunda infância, na relação entre pares da mesma idade, há a satisfação de necessidades de afiliação, compartilhamento de brincadeiras e identificações com os outros. Assim, não só a família se torna agente socializador de importância na infância, mas outras interações que ampliam sua rede de relações sociais podem contribuir decisivamente para o desenvolvimento

As autoras apontam para algumas mudanças que têm ocorrido nas relações sociais das famílias, como menor tempo de contato entre os cônjuges e seus filhos, maior exposição das crianças à TV e a outros grupos que orientam tarefas e lazer.

Dessa forma, é preciso avaliar a interação direta dos pais com seus filhos, hoje restrita a períodos de tempo curtos, com interações familiares que podem ser caracterizadas como de baixos níveis de interação face $-\mathrm{a}$ face em atividades compartilhadas.
Em relação às famílias em situação de pobreza, Zamberlan e Biasoli-Alves (1997) dizem que elas se encontram em situação de risco, pois vivem sem uma rede de apoio de parentes, vizinhos e amigos, para superar os momentos de estresse. Nunes (1994) ressalta que crescer na pobreza é uma ameaça ao bemestar das crianças e uma limitação às suas oportunidades de desenvolvimento. A pobreza está associada a um aumento da incidência tanto de problemas socioemocionais como cognitivos. McLoyd (citado por Nunes, 1994) argumenta que a privação econômica e a pobreza afetam as crianças indiretamente, mediante seu impacto no comportamento dos pais, impacto que depende da qualidade das relações entre a mãe e o pai. De acordo com Alves (2000), os estudos com crianças em situação de risco, de modo especial em situação de pobreza, geralmente baseiam-se em delineamentos descritivos e exploratórios, procurando caracterizar seu desenvolvimento socioemocional dentro de parâmetros contextuais sócio-histórico-culturais. Neste estudo apresentado, o referencial teórico e metodológico é a Teoria dos Sistemas Ecológicos, proposta por Urie Bronfenbrenner. Nessa teoria o autor descreve quatro dimensões dinamicamente relacionadas, as quais representam características do processo evolutivo para todas as fases do ciclo vital. Estas dimensões incluem o tempo (história presente e passada da humanidade em geral, e longitudinalmente, das pessoas estudadas em específico), a pessoa (o indivíduo em si, com suas características biopsicológicas), o processo (experiências cotidianas, pares de interação e significados internalizados) e o contexto (ambientes físico-sociais onde ocorrem a socialização e o contato com valores, culturas, ideologias, etc.). Para Bronfenbrenner (1979/1996), o contexto é uma dimensão que abrange quatro diferentes sistemas de interação entre pessoa e ambiente, sempre interligados e atuantes. Estes sistemas podem ser apresentados como microssistema, mesossistema, exossistema e macrossistema.

$\mathrm{O}$ microssistema refere-se àqueles ambientes onde a interação ocorre face a face, entre a pessoa em desenvolvimento e os outros, assim como entre ela e objetos e símbolos. O mesossistema é definido como a interligação dos diversos microssistemas aos quais pertence a pessoa em desenvolvimento, ocorrendo relações que resultam na composição de uma rede de microssistemas. A família, a escola, os vizinhos e os grupos comunitários podem integrar o mesossistema. O exossistema refere-se ao espaço de interação e convivência onde a pessoa em desenvolvimento não se encontra presente, mas no qual sofre a influência 
direta da dinâmica de interações de quem dele participa. O macrossistema: representa a cultura na qual está inserida a pessoa em desenvolvimento; refere-se ao conjunto de crenças e valores, às regras e aos papéis esperados e difundidos dentro deste contexto mais amplo, além dos aspectos econômicos, sociais e históricos.

O estudo apresentado procura associar questões do contexto e do processo (o lúdico enquanto fator mediador do desenvolvimento, o favorecimento de relações sociais na família, os esteriótipos, crenças e valores associados ao ser-criança e ao brincar) na Teoria dos Sistemas Ecológicos com as vivências e expectativas dos familiares destas crianças sobre o brincar, os brinquedos, brincadeiras, os espaços e interações ocorridas durante a realização de atividades lúdicas. O enfoque, portanto, será dado aos aspectos interacionistas presentes neste processo. A análise do contexto e processo pode vir a fornecer dados que permitam a implantação de estratégias que visem uma maior interação entre os sistemas nos quais a criança está inserida, uma vez que estes estudos apontam para a importância disto no desenvolvimento integral do indivíduo.

\section{MÉTODO}

Fizeram parte deste estudo 40 crianças entre sete e dez anos e um dos familiares/cuidadores de cada uma delas, as quais eram freqüentadoras de duas escolas municipais de Caxias do Sul. Foram incluídas famílias de nível socioeconômico baixo, definido como situação de pobreza, de acordo com Pastore, Zylberstain e Pagotto (1983), com menos de 1/4 de salário mínimo regional de renda per capita.

Para a coleta de dados foram utilizados os seguintes instrumentos: o jogo das sentenças incompletas, para as crianças e familiares/cuidadores, e uma entrevista estruturada, para coleta dos dados sociodemográficos realizada com os familiares/cuidadores. Para a análise das respostas das crianças e familiares às sentenças incompletas, foi adotado o modelo quantitativo-interpretativo proposto por Alves e cols. (2001), que determina o seguinte procedimento de avaliação das respostas obtidas.

a) Investigação: é o momento no qual se investiga cada comportamento ou resposta apresentada, que são classificandos segundo a proximidade de sentido que apresentam. Este procedimento permite um agrupamento inicial dos dados (por exemplo, as respostas "brincar é bom" e "brincar para mim é legal" possuem uma proximidade de sentido, que indica a satisfação da criança ao realizar a atividade). Nesta etapa, objetiva-se compreender o significado e a importância do dado coletado para os objetivos do estudo, além de analisar a relevância e adequação do instrumento utilizado, frente aos estudos obtidos.

b) Categorização: é o momento no qual, através de um estudo minucioso de cada comportamento ou fala dos participantes, surgem os agrupamentos válidos dos dados. Os critérios utilizados para a criação destes agrupamentos (categorias) serão: exaustividade (análise de todas as formas de respostas obtidas), exclusividade (cada categoria classifica um grupo de respostas) e manutenção (as categorias devem ter um mesmo nível de interferência e interpretação das respostas, evitando-se grandes oscilações no contínuo objetividade-subjetividade).

Os dados sociodemográficos foram analisados com vistas a identificar um quadro descritivo da situação financeira e familiar dessas crianças.

Os dados coletados no jogo das sentenças foram tabelados através da contagem das categorias agrupadas.

Para a categorização das respostas em relação aos brinquedos utilizou-se a classificação de Tudge, Sidden e Putnam (1994) para agrupar os brinquedos denominados acadêmicos, que são aqueles criados com a finalidade de aprendizagem. Tais brinquedos Incluem papel, tesourinha, lápis de cor, livros de estória, etc. As brincadeiras livres, correspondentes àquelas de correr e pular, que envolvem atos motores, foram agrupadas como pertencentes à categoria de jogos de exercícios da classificação citada por Piaget.

\section{RESULTADOS}

Os resultados apresentados a seguir foram obtidos através das sentenças incompletas realizadas pelas crianças e seus respectivos familiares/cuidadores, com relação ao brincar. As sentenças foram agrupadas em módulos, através dos quais é possível verificar as categorias de respostas, suas freqüências e percentuais.

Os resultados deste estudo são discutidos com vista a integrar os dados das entrevistas realizadas junto aos familiares/cuidadores com os obtidos nas sentenças incompletas destes e de seus filhos. Essa integração objetiva a análise de fatores relativos ao brincar quanto ao desenvolvimento infantil e à promoção da resiliência. 


\section{Resultados obtidos dos dados sociodemográficos}

Os dados biossociodemográficos da amostra revelam um quadro descritivo da situação das crianças. É importante, primeiramente, considerar os dados relativos à sua idade e à sua escolaridade. De acordo com os dados, quatro crianças a mais estão na $1^{\circ}$ série, uma vez que apenas 9 têm 7 anos, mas 13 estão freqüentando a $1^{\circ}$ série. Pode-se pensar que essa defasagem entre série e idade da criança ocorra por repetência, abandono temporário ou entrada tardia na escola. Os demais estão dentro da série esperada para suas idades. Isso sugere que a grande maioria destas crianças possui um desenvolvimento cognitivo adequado à sua idade, uma vez que acompanham as séries de acordo com o cronologicamente esperado. Apesar de viverem em situação de pobreza, caracterizada, em sua maioria, com $65,0 \%$ que vivem com uma renda per capita de $\mathrm{R} \$ 60,00$, esse fator parece não ter afetado a vida escolar destas crianças. Elas têm freqüentado a escola, que é um espaço propício para a socialização ao mesmo tempo um espaço que privilegia a construção de conhecimentos e de habilidades específicas, tanto intelectuais como físicas. Portanto, são crianças que não estão envolvidas com outras atividades que substituam a escola, o que é um fator positivo na vida delas.

Com relação à escolaridade das mães, os dados demonstram que $80,0 \%$ destas têm o primeiro grau incompleto, demonstrando sua baixa escolaridade. Em relação com isto, observa-se que a ocupação da maior parte das mães é ser dona-de-casa ou doméstica, o que sugere ser cada vez mais difícil empregar pessoas com baixa escolaridade e qualificação. Da mesma forma, os dados obtidos dos pais revelam que $15,0 \%$ deles não estudaram e $45,0 \%$ têm o primeiro grau incompleto. Semelhantemente ao que se verificou com as mães, apenas 10,0\% deles têm o $1^{\circ}$ grau completo. A ocupação dos pais também revela as baixas condições de trabalho que possuem, sendo que a maioria tem empregos horistas e demais empregos temporários. Há ainda cinco pais que não trabalham. Os empregos dos pais das crianças, associados com a renda per capita de até $1 / 4$ do salário mínimo e a baixa escolaridade, permitem pressupor condições precárias em nível intelectual e socioafetivo com as quais estas famílias convivem. Um fato que parece ser favorável é o de que $70,0 \%$ da amostra têm casa própria e a maior parte das famílias tem até 3 filhos. De acordo com Luthar e Zigler (1991), o nível socioeconômico está entre os índices de estresse mais investigados. Os fatores que podem operar como risco são: ocupação de baixo status dos pais, baixa escolaridade, famílias numerosas e ausência de um dos pais. Com relação à ausência dos pais, os dados apontam para vinte e cinco pais casados, doze separados e três viúvos; há, portanto, a presença do casal de pais em $62,5 \%$ da amostra, diminuindo também o aspecto da ausência de um dos pais como fator de risco. Porém, isso não revela qualidade e interação da vida do casal, que também constituem um fator importante a ser considerado para determinar que a união do casal seja um fator de risco ou proteção.

\section{Resultados obtidos com o jogo das sentenças incompletas}

Com relação ao significado e função do brincar, os pais e seus filhos tiveram respostas semelhantes em relação ao prazer despertado pelo brincar. Este é um aspecto que fica bastante evidente tanto para os pais como para seus filhos, pois ambos associam o brincar com o sentimento de ser legal, bom. As crianças relacionam o brincar às atividades e às companhias; enquanto as associações dos pais refletem suas próprias concepções de infância. Para eles, criança brinca porque é criança, porque não tem outra coisa para fazer. Inclusive justificam essas concepções com as respostas referentes à função do brincar: a de satisfazer porque dá prazer, a de distrair porque não tem outra coisa para fazer. Alguns ainda introduzem a idéia de que o brincar também serve para o desenvolvimento, e outros não definiram nenhuma função, sugerindo a carência de orientações em relação àquilo que os jogos, brinquedos e brincadeiras podem estimular, desenvolver e/ou promover.

Em relação às preferências e desejos, os pais citam os seguintes brinquedos como seus preferidos: jogos, os brinquedos industrializados e os acadêmicos. Em relação à preferência de seus filhos, os mais citados foram: os industrializados, os jogos e os acadêmicos. As crianças citaram com mais freqüência como sendo seus brinquedos preferidos: os industrializados, a bicicleta, a patinete e a bola. Aqueles que gostariam de ter apresentam uma diferença apenas quantitativa. Quanto ao brinquedo, então, percebe-se que os pais introduziram os jogos e os brinquedos acadêmicos na preferência dos filhos, quando seriam da preferência deles, pois não citaram os jogos nem os acadêmicos num percentual tão relevante. Analisando a Tabela 1, podemos sugerir que talvez, quando os pais brincam com seus filhos, estes 
brinquedos citados por eles sejam os preferidos por serem também os mais aceitáveis, porque os jogos são o material lúdico dos adultos, e não se restringem a uma faixa etária, de acordo com Brougère (1994).

Tabela 1. Brinquedos: Preferências e Desejos para os pais: Sentenças, Respostas, Freqüências e Percentual de Respostas por Categoria

\begin{tabular}{|c|c|c|}
\hline Sentença & Freqüência & Percentual \\
\hline \multicolumn{3}{|l|}{ Queria que o filho brincasse de... } \\
\hline Jogos (vídeo, montar,...) & 21 & 52,5 \\
\hline Boneca, carrinhos, $\ldots$ & 10 & 25,0 \\
\hline Brinquedos acadêmicos (livros, escolinha...) & 8 & 20,0 \\
\hline Não tem preferência & 1 & 2,5 \\
\hline \multicolumn{3}{|l|}{ Brinquedo mais legal para o filho é... } \\
\hline Boneca, carrinho & 17 & 42,5 \\
\hline Jogos & 14 & 35,0 \\
\hline Brinquedos acadêmicos & 5 & 12,5 \\
\hline Andar de bicicleta & 5 & 7,5 \\
\hline Brinquedos que ele cria & 3 & 2,5 \\
\hline Gosta de brincar com ele de... & 11 & 27,5 \\
\hline Jogos & 7 & 17,5 \\
\hline Brinquedos acadêmicos & 7 & 17,5 \\
\hline Boneca, carrinho & 6 & 15,0 \\
\hline Brincadeiras livres & 1 & 2,5 \\
\hline Passear & 4 & 10,0 \\
\hline Não tem preferência & 4 & 10,0 \\
\hline \multicolumn{3}{|l|}{ Não brinco } \\
\hline \multicolumn{3}{|l|}{ Filho(a) pede para brincar de... } \\
\hline Não pede & 12 & 30,0 \\
\hline Jogos & 10 & 25,0 \\
\hline Brincadeiras livres & 8 & 20,0 \\
\hline Brinquedos acadêmicos & 5 & 12,5 \\
\hline Boneca, carrinho & 4 & 10,0 \\
\hline Não tem preferência & 1 & 2,5 \\
\hline
\end{tabular}

Em relação às brincadeiras livres, é relevante que os pais, em sua maioria, não as citaram como sendo as preferidas pelas crianças. elas aparecem para alguns pais ao brincarem com os filhos ou ao serem por estes solicitados. Mas as crianças citaram num percentual de $65,0 \%$ as brincadeiras livres como aquelas que mais gostam e num percentual de $70,0 \%$, como aquelas que mais gostariam de brincar. Elas são também as brincadeiras mais utilizadas por eles, atingindo um percentual de $70,0 \%$. A diferença de respostas encontradas neste item revela, associadas com a Tabela 2, que estas brincadeiras são as que mais se repetem quando as crianças estão na companhia de irmãos, primos e amigos, e na rua. Talvez esse aspecto possa justificar a falta desta indicação de respostas pelos pais, pois na rua as crianças ficam menos assistidas do que quando estão em casa. Isso significa que, mesmo não sendo muitas as crianças que brincam na rua, como posteriormente vamos ver, não há, ou há pouca supervisão dos adultos quando elas brincam na rua, coincidindo este dado com achados da pesquisa de Alves e cols. (2001).

Tabela 2. Companhias das Crianças para Brincar: Sentenças, Respostas, Frequiências e Percentuais de Respostas por Categorias.

\begin{tabular}{|c|c|c|}
\hline \multicolumn{3}{|c|}{ Módulo 8- Companhias na Visão das Criancas $(N=40)$} \\
\hline Sentenca & Frequência & Percentual \\
\hline \multicolumn{3}{|c|}{ Quando você está em casa brinca com quem... } \\
\hline Irmãos, primos, amigos & 34 & 85,0 \\
\hline Mãe/pai & 4 & 10,0 \\
\hline Sozinho & 2 & 5,0 \\
\hline \multicolumn{3}{|c|}{ Quando está na rua brinca com quem... } \\
\hline Irmãos, primos, amigos & 35 & 87,5 \\
\hline Sozinho & 3 & 7,5 \\
\hline Mãe/pai & 2 & 5,0 \\
\hline \multicolumn{3}{|c|}{ Você e seus amigos brincam de... } \\
\hline Brincadeiras livres & 28 & 70,0 \\
\hline Escolinha, família & 9 & 22,5 \\
\hline Não brinco & 3 & 7,5 \\
\hline \multicolumn{3}{|l|}{ Brinca na rua de que... } \\
\hline Brincadeiras livres & 27 & 67,5 \\
\hline Carrinho, bicicleta & 7 & 17,5 \\
\hline Não brinco & 6 & 15,0 \\
\hline \multicolumn{3}{|l|}{ Brinca em casa de... } \\
\hline Boneca, carrinho & 26 & 65,0 \\
\hline Brincadeiras livres & 6 & 15,0 \\
\hline Jogos & 4 & 10,0 \\
\hline Brinquedos acadêmicos & 3 & 7,5 \\
\hline Não brinca em casa & 1 & 2,5 \\
\hline
\end{tabular}

Os dados da Tabela 3 confirmam também que os pais possuem pouco tempo para brincar com os filhos, uma vez que quando estes estão em casa ou na rua ocupam-se geralmente com serviços de casa. Quando não estão ocupados com serviços de casa, $57,5 \%$ dos pais disseram ocupar seu tempo com os filhos conversando, portanto não brincando, ou brincando pouco com brincadeiras, brinquedos ou jogos. As crianças reforçam estas questões, não referindo brincar com adultos, sendo outras as companhias que possuem para brincar em casa e na rua. Estes dados revelam a realidade das crianças e suas famílias: há o reconhecimento por parte dos pais de que precisam brincar e há por parte das crianças a necessidade de companhias, que são os irmãos, amigos ou primos, na maior parte. Esse dado é preocupante, pois, a interação com o adulto pode proporcionar a passagem de valores e crenças e fortificar laços afetivos. Um adulto participativo nas atividades de brinquedo pode, segundo Alves e cols. (2001), favorecer as trocas entre gerações e a aprendizagem da construção de brinquedos e jogos populares. 
Tabela 3. Tempo e Companhia dos Filhos para Brincar: Sentenças, Respostas, Freqüências e Percentuais de Respostas por Categoria

\begin{tabular}{|c|c|c|}
\hline Sentenca & Frequência & Percentual \\
\hline \multicolumn{3}{|l|}{ Tempo do filho para brincar } \\
\hline Um período por dia e final de semana & 30 & 75,0 \\
\hline Finais de semana & 5 & 12,5 \\
\hline Até 2 horas/dia & 3 & 7,5 \\
\hline Dois períodos /dia & 2 & 5,0 \\
\hline \multicolumn{3}{|l|}{ Tempo que brincam juntos } \\
\hline Menos de 1 hora/dia & 18 & 45,0 \\
\hline Um período/dia & 8 & 20,0 \\
\hline Final de semana & 7 & 17,5 \\
\hline Não brincamos & 6 & 15,0 \\
\hline Um período dia/final de semana & 1 & 2,5 \\
\hline \multicolumn{3}{|l|}{ O que fazem juntos } \\
\hline Conversar & 5 & 12,5 \\
\hline Serviços de casa & 3 & 7,5 \\
\hline Assistir TV & 2 & 5,0 \\
\hline Passear & 25 & 62,5 \\
\hline Brincar & 6 & 15,0 \\
\hline \multicolumn{3}{|l|}{ Quando ele brinca você faz: } \\
\hline Serviços da casa & 5 & 12,5 \\
\hline Não deixo brincar na rua & 3 & 7,5 \\
\hline Vou junto com ele & 1 & 2,5 \\
\hline Atividades com ele e serviços da casa & 32 & 80,0 \\
\hline Trabalho fora & 6 & 15,0 \\
\hline \multicolumn{3}{|c|}{ Quando ele brinca em casa ocupa seu tempo com } \\
\hline \multicolumn{3}{|l|}{ Serviços da casa } \\
\hline \multicolumn{3}{|l|}{ Servicos da casa e atividades com ele } \\
\hline Trabalha fora & 1 & 2,5 \\
\hline Assiste TV & 1 & 2,5 \\
\hline
\end{tabular}

Apesar de disporem de pouco tempo para brincar com seus filhos, a casa foi o local escolhido por $77,5 \%$ dos pais como sendo o preferido para brincarem juntos, ao mesmo tempo que é o local onde $80,0 \%$ dos pais responderam brincar mais. A rua foi citada por $87,5 \%$ dos pais como um local não satisfatório para que seus filhos brinquem. As crianças citaram a casa como o lugar onde mais brincam, com percentual de 55,0\%; mas a rua e o parque também apareceram como lugares preferenciais. As razões das crianças para brincarem na rua se assemelham às dos pais: ter mais espaço e ser bom. Alguns também as associaram com as brincadeiras livres e as companhias. Os brinquedos industrializados e os jogos foram os mais citados como aqueles ideais para brincar em casa. Os pais associam a preferência de as crianças brincarem em casa com a segurança, o controle; já as crianças a associam com mais freqüência com: as companhias dos irmãos, amigos e primos, com o sentimento de ser bom e ser menos perigoso. Poucas crianças citaram a casa dos avós, dos amigos e a escola como lugares preferidos ou frequientes de brincar, sugerindo que há pouca circulação destas crianças em ambientes que não seja o do lar. Isso torna necessária uma maior investigação em relação às características destas redes de apoio (vizinhos, parentes, escola), uma vez que elas não sugerem ser locais associados ao prazer na realização destas atividades lúdicas citadas pelas crianças como preferidas e freqüentes.

Em relação ao significado do trabalho dos pais, estes avaliam sua importância pela necessidade e prazer. Já as crianças, referindo-se aos trabalhos diários de casa, na sua grande maioria, demonstram sentir prazer. O prazer está associado ao fato de sentirem estar ajudando os pais, de gostarem de exercer determinadas tarefas, havendo uma compreensão da necessidade de sua participação em casa. Interessante ressaltar que é possível estar o sentimento de bem-estar das crianças associado à certeza de estarem realizando algo útil e socialmente aceito. Trabalhar parece estar presente na construção da identidade destas crianças. Ainda há a questão de que pensam, sobretudo, em brincar depois do trabalho. Isso indica que o trabalho é uma tarefa impeditiva do exercício do lúdico. A importância das tarefas diárias parece ser maior do que a de brincar, e talvez por isso elas responderam que preferem trabalhar, como uma resposta mais valorizada pelo ambiente do que o próprio brincar. $\mathrm{O}$ dever dos pais de trabalhar parece ser algo valorizado em relação ao sustento da família, uma vez que este é o foco de seus pensamentos enquanto trabalham.

\section{CONCLUSÕES}

Os resultados deste estudo apresentam os brinquedos e brincadeiras diárias das crianças em relação ao seu contexto sociofamiliar, bem como a compreensão de seus familiares/cuidadores em relação ao lúdico. $\mathrm{O}$ método empregado possibilitou $\mathrm{o}$ conhecimento a respeito do brincar destas crianças, incluindo os objetos escolhidos, tempo, espaço e companheiros que fazem parte deste processo; além disto, possibilitou uma aproximação das vivências e trocas realizadas com os adultos, através do lúdico ou não.

Esta investigação demonstra vários pontos favoráveis para o seu desenvolvimento, os quais foram, em relação às crianças:

- as crianças associam prazer ao brincar e em geral elas têm: tempo, espaço e companhia para brincar, dispondo de brinquedos e brincadeiras diárias preferidas; 
- há uma rede social para trocas de normas, valores e crenças;

- as crianças freqüentam a escola e habitam seu próprio lar, possuindo contato com familiares/cuidadores;

- há a noção de trabalho na construção da identidade destas crianças;

- o lar é um local que oferece segurança e espaço para brincar.

Em relação aos familiares/cuidadores, podemos considerar os seguintes aspectos favoráveis:

- há compreensão a respeito da necessidade das crianças em brincar;

- eles favorecem tempo, espaço e companhia para que as crianças brinquem;

- quando solicitados e lhes é possível, em grande parte, conseguem ter prazer nas atividades lúdicas realizadas com seus filhos;

- utilizam-se dos jogos, que desenvolvem o pensamento das crianças, e das conversas quando se ocupam com as crianças;

- a casa é um local valorizado, por ocorrerem com maior freqüência as atividades lúdicas com as crianças, sendo associada a sentimentos de segurança e de lazer;

- distribuem tarefas domésticas para as crianças, num sentido de colaboração e ajuda mútua, conforme respostas dadas pelas crianças;

- trabalham, na maior parte, comprometidos com o bem-estar da família.

Também podemos levantar vários aspectos relativos às crianças e aos familiares/cuidadores considerados mais desfavoráveis:

- A escola, em geral, não é citada como um local de referência para o brincar, demonstrando que, apesar de freqüentarem-na, há uma desvinculação do ambiente escolar com a realidade cotidiana destas crianças, muito mais exigindo normas e aprendizagens do que se oferecendo como um local prazeroso para o desenvolvimento de atividades lúdicas. Sabe-se que os jogos competitivos, os jogos que estimulam estratégias, bem como a motricidade, podem e deveriam ser estimulados por essa instituição, favorecendo assim a capacidade de raciocínio e outras habilidades corporais e sociais necessárias para lidar com as diversas circunstâncias da vida.

- A excessiva utilização e preferência por brinquedos industrializados necessitam melhor investigação quanto à apropriação que as crianças fazem com tais brinquedos, a fim de verificar a possibilidade de criarem e recriarem novos significados.

- A baixa referência aos brinquedos de criação sugere que há pouca estimulação e valorização da criatividade das crianças, criatividade que poderia ser mais valorizada pelos ambientes nos quais as crianças interagem diretamente: lar, escola, etc...

- Houve poucos dados referentes a locais como casa dos amigos, parentes e avós como favoráveis ao desenvolvimento de atividades lúdicas, sugerindo que a rede social dessa população restringe-se ao seu próprio lar, o que limita, para a criança, interações possíveis entre os diversos locais freqüentados. Houve poucos dados que possam servir de comparativos com relação ao seu lar.

- Os familiares/cuidadores possuem muito pouco tempo para realizar atividades lúdicas com seus filhos ou acompanhá-los na realização de tais atividades, sugerindo que haja poucas trocas afetivas, poucas passagens em relação a normas, valores, crenças, etc.

- Os familiares/cuidadores têm ocupação de baixo status e baixa escolaridade, o que pode relacionado à satisfação de suas necessidades de auto-estima, reconhecimento, a sentimentos de baixa autoestima, depressão, cansaço, agressividade, etc., acarretando prejuízos nos níveis de interação com seus filhos.

Considerando-se as questões acima, é importante pensar em novas pesquisas que possam observar in loco as interações ocorridas entre as crianças e seus iguais e as crianças e seus familiares/cuidadores, a fim de que possam ser avaliados os níveis de apropriação de significados, norma e valores que são realizados enquanto se desenvolvem as atividades lúdicas.

Também as conclusões sugerem que se possa pensar em programas que beneficiem as interações entre os familiares/cuidadores e as crianças através do lúdico, abrangendo os diferentes ambientes freqüentados pela criança, a fim de que o lúdico possa servir como instrumento de mediação nas diversas relações. A escola pode servir de local facilitador para que algumas atividades lúdicas possam acontecer, permitindo a interação maior entre escola e família, ao mesmo tempo que pode favorecer uma maior proximidade entre familiares/cuidadores e crianças. A promoção de jogos que desenvolvam o aspectos cognitivo e social destas crianças pode encorajar e reforçar as capacidades das crianças para lidar com as diversas circunstâncias da vida. 
Sugere-se que o método da observação in loco possa ser acrescentado num próximo estudo, para que se possa averiguar a qualidade das interações ocorridas; bem como a realização de estudos com crianças de classe econômica mais favorecida, a fim de comparar os dados obtidos.

\section{REFERÊNCIAS}

Alves, P., Koller, S., Silva, M., Santos, C., Silva, A., Reppold, C. \& Prade, L. (2001). Brinquedo, trabalho, espaço e companhia de atividades lúdicas no relato de crianças em situação de rua. Psico, 32(2), 47-71.

Alves, P. (2000). O modelo dos sistemas ecológicos e o desenvolvimento de crianças em situação de rua: infância, tempo e atividades cotidianas. Tese de Doutorado não publicado. Programa de Pós-Graduação em Psicologia do Desenvolvimento, Universidade Federal do Rio Grande do Sul, Porto Alegre.

Amorim, C., Oliveira, M. \& Mariotto, R. (1997). A Psicologia do brinquedo. Revista Psicologia Argumento, 15(21), 9-31.

Bronfenbrenner, U. (1996). A Ecologia do Desenvolvimento Humano. Porto Alegre, Artes Médicas. (Trabalho original publicado em 1979).

Brougère, G. (1994). Brinquedo e Cultura. São Paulo: Cortez.

Kotliarenco, M. (2002). El Juego como possibilidad de refuerzo a la Resiliencia. Em: Santos, S. (Org.)
Brinquedoteca (pp 41-43). Rio de Janeiro, Vozes. (Trabalho original publicado em 1997).

Luthar, S. S., \& Zigler, E. (1991). Vulnerability and competence. A review os research on resilience in childhood. American Journal os Orthopsychiatry, 61, 6-22.

Nunes, T. (1994). O ambiente da criança. Cadernos de Pesquisa, 89, 5-23.

Oliveira, P. S. (1984). O que é brinquedo. São Paulo: Brasiliense.

Pastore, J., Zylberstain, H. \& Pagotto, C. (1983). Mudança social e pobreza no Brasil: 1970-1980. São Paulo, Pioneira.

Poletto, R., Koller, S. (2002). A rede de apoio social e afetivo em crianças em situação de pobreza. Psico, 33(1), 151-175.

Tudge, J., Sidden, J., \& Putnam, S. (1994). The cultural ecology of young children. (Manuscrito não-publicado).

Vygotsky (1989). A formação social da mente. São Paulo: Martins Fontes.

Zamberlan, M. T. \& Biasoli-Alves, Z. M. (1997). Interações familiares. Teoria pesquisa e Subsídios à intervenção. Londrina: Eduel.

Winnicott, D. (1982). A criança e seu mundo. Rio de Janeiro. Editora Guanabara Koogan S. A.

Recebido em 05/04/2004 Aceito em 24/10/2004

Endereço para correspondência: Raquel Conte Poletto. R. Ângelo de Carli, 1110 ap. 201, CEP 95055-090, Caxias do Sul -RS. E-mail: rcpoletto@ig.com.br 